\title{
PWT1, an Avirulence Gene of Magnaporthe oryzae Tightly Linked to the rDNA Locus, Is Recognized by Two Staple Crops, Common Wheat and Barley
}

\author{
Izumi Chuma, Su-Wen Zhan, Shunsuke Asano, Nguyen Thi Thanh Nga, Trinh Thi Phuong Vy, \\ Michiko Shirai, Kana Ibaragi, and Yukio Tosa
}

Laboratory of Plant Pathology, Graduate School of Agricultural Sciences, Kobe University, Nada, Kobe 657-8501, Japan.

Accepted for publication 21 December 2009.

\begin{abstract}
Chuma, I., Zhan, S.-W., Asano, S., Nga, N. T. T., Vy, T. T. P., Shirai, M., Ibaragi, K., and Tosa, Y. 2010. PWT1, an avirulence gene of Magnaporthe oryzae tightly linked to the rDNA locus, is recognized by two staple crops, common wheat and barley. Phytopathology 100:436-443.

The pathogenicity to wheat (Pwt1) locus conditions host species specificity of Magnaporthe oryzae on wheat. GFSI1-7-2 (Setaria isolate) carries the avirulence allele ( $P W T 1)$ at this locus while $\mathrm{Br} 48$ (Triticum isolate) carries the virulence allele ( $p w t 1)$. An $\mathrm{F}_{1}$ culture derived from a cross between GFSI1-7-2 and $\mathrm{Br} 48$ was backcrossed with $\mathrm{Br} 48$ to produce a tester population in which $P W T 1$ alone segregated. When hexa-

ploid wheat lines were inoculated with the $\mathrm{BC}_{1} \mathrm{~F}_{1}$ testers, they were all resistant to all $P W T 1$ carriers and susceptible to all pwt 1 carriers, suggesting that they recognize $P W T 1$. When barley cultivars were inoculated with the testers, they showed the same pattern of reactions as the hexaploid lines, suggesting that the barley cultivars also recognize PWT1. These results suggest that $P W T 1$ is a fundamental gene that universally conditions the avirulence of Setaria isolates on two staple crops, hexaploid wheat and barley. Interestingly, tetraploid wheat lines did not recognize $P W T 1$. Molecular mapping using the $\mathrm{F}_{1}$ and $\mathrm{BC}_{1} \mathrm{~F}_{1}$ populations revealed that the Pwt1 locus is located on chromosome 2 and tightly linked to the ribosomal DNA locus and a telomere.
\end{abstract}

The filamentous ascomycete fungus Magnaporthe oryzae (2) causes blast disease on many gramineous plants. This fungus exhibits a high degree of host specificity. On the basis of host range, mating ability, and genetic relatedness, $M$. oryzae isolates are classified into several host-specific subgroups or pathotypes; for example, the Oryza pathotype, pathogenic on rice (Oryzae sativa L.); the Setaria pathotype, pathogenic on foxtail millet (Setaria italica Beauv.); the Triticum pathotype, pathogenic on wheat (Triticum aestivum L.); and the Avena pathotype, pathogenic on oat (Avena sativa L.) $(10,16,22)$. The Oryza and Setaria pathotypes contain physiological races which show various patterns of virulence on cultivars within their host species.

Race-cultivar specificity (or cultivar specificity) (5) has long been a major research topic in the $M$. oryzae-gramineous plant system. Silue et al. (19) demonstrated that race-cultivar specificity is controlled by gene-for-gene interactions. Valent and coworkers cloned Pita, a rice gene that confers resistance to races of the rice pathogen (1), and its corresponding avirulence gene, AVR-Pita (17). They suggested that their products bind together inside the plant cell to initiate a defense response (8).

On the other hand, genetic mechanisms of host species specificity (or plant species specificity) (5) remain to be elucidated. A preliminary genetic analysis was performed by Yaegashi (27). He crossed Eleusine isolates (isolates from finger millet, Eleusine coracana) with Eragrostis isolates (isolates from weeping love-

Corresponding author: Y. Tosa; E-mail address: tosayuki@kobe-u.ac.jp

* The $e$-Xtra logo stands for "electronic extra" and indicates that the online version contains a table showing the marker descriptions and segregation patterns in $78 \mathrm{~F}_{1}$ cultures and a figure showing the structure of the supercontig 1 of the genome sequence of $M$. oryzae strain 70-15.

doi:10.1094/PHYTO-100-5-0436

(C) 2010 The American Phytopathological Society grass, Eragrostis curvula), inoculated finger millet and weeping lovegrass with their $F_{1}$ cultures, and suggested that a single gene was involved in the specific parasitism on each host. Valent and coworkers (24) identified PWL1 and PWL2, major genes involved in the species specificity of the Eleusine pathotype and the Oryza pathotype, respectively, toward weeping lovegrass. These genes were successfully cloned $(9,20)$, and were revealed to function as avirulence genes.

Our laboratory started a systematic genetic analysis of host species specificity. We chose a Triticum isolate $(\mathrm{Br} 48)$ as a common parent for crossing because it is highly fertile with other isolates of M. oryzae. Murakami et al. (12) crossed the Triticum isolate with a Setaria isolate (GFSI1-7-2), and inoculated a wheat cultivar with their $F_{1}$ cultures. Segregation analyses revealed that two loci, designated as Pwtl and Pwt2, were involved in the specific parasitism of the parental isolates on wheat. Subsequently, Takabayashi et al. (21) crossed the Triticum isolate with an Avena isolate (Br58) and identified two other loci, Pwt3 and Pwt4, which were involved in the specific parasitism of the parental isolates on wheat. Further, Tosa et al. (23) crossed the Triticum isolate with an Oryza isolate (PO12-7301-2) and showed that three loci, Pwt1, Pwt2, and Pwt5, were involved in the specific parasitism of the parental isolates on wheat. From circumstantial evidence, they assumed that $P w t 1$ to 5 are avirulence loci or, in other words, that avirulence alleles are functional. Based on this assumption, the avirulence/virulence alleles at these loci were designated as PWT1/pwt1, PWT2/pwt2, PWT3/pwt3, $P W T 4 / p w t 4$, and $P W T 5 / p w t 5$, respectively $(21,23)$.

The $\mathrm{F}_{1}$ hybrids carrying PWT4 were avirulent on wheat cv. Norin 4 but virulent on another wheat cultivar, Chinese Spring (21). By using this "cultivar specificity", Takabayashi et al. (21) successfully identified the first wheat gene for resistance to $M$. oryzae and designated it as Rmgl, with Rwt4 listed as a synonym. Rwt4 corresponded to PWT4 in a gene-for-gene manner (7). These results suggested that $P w t 4$ is actually an avirulence locus 
and that gene-for-gene interactions also underlie host species specificity (21). Then, a question arises: what is the difference between avirulence genes involved in cultivar specificity and those involved in species specificity?

In the present study, we focused on the PWT1 gene which conditions avirulence of the Setaria and Oryza pathotypes on wheat. One possible difference between the avirulence genes involved in cultivar specificity and those involved in species specificity may be the range of plant species that recognize them. To determine the range of plant species which recognize PWT1, various accessions of wheat and barley were inoculated with a tester population of $M$. oryzae. Another possible difference between the two categories of avirulence genes may be in their stability. Avirulence genes involved in cultivar specificity tend to be located on subtelomeric regions, which are known to be hypervariable $(3,18)$. To identify the chromosomal region carrying $P W T 1$, a linkage analysis was performed using chromosomespecific restriction fragment length polymorphism markers and telomere repeats as probes. The analysis revealed that $P W T 1$ was tightly linked to the ribosomal DNA (rDNA) locus and a telomere.

\section{MATERIALS AND METHODS}

Fungal strains. $M$. oryzae strains used in the present study were descendants of GFSI1-7-2 (a Setaria isolate collected in Japan in 1977) and Br48 (a Triticum isolate collected in Brazil in 1990). Genotypes of these field isolates are PWT1;PWT2;pwt3; pwt4;pwt5 and pwt1;pwt2;pwt3;pwt4;pwt5, respectively (23). GFSI1-7-2 has the MAT1-2 allele at the mating-type locus while Br48 has the MATI-1 allele. Murakami et al. (12) crossed these isolates and produced $80 \mathrm{~F}_{1}$ cultures in which PWT1 and PWT2 segregated. To produce a tester population in which $P W T 1$ alone segregated, 3M2 (PWT1;pwt2;pwt3;pwt4;pwt5) with the MAT1-2 allele was chosen from the $F_{1}$ cultures and backcrossed with Br48 on oatmeal agar medium ( $20 \mathrm{~g}$ of oatmeal, $10 \mathrm{~g}$ of agar, and $2.5 \mathrm{~g}$ of sucrose in $500 \mathrm{ml}$ of water) as described previously (12). One ascospore was arbitrarily chosen from ascospores in each ascus and isolated. The resulting $\mathrm{BC}_{1} \mathrm{~F}_{1}$ population was composed of 63 cultures (derived from 63 asci).

To produce an $F_{1}$ population for fine mapping, GFSI1-7-2 was again crossed with $\mathrm{Br} 48$ on oatmeal agar medium. The progeny was isolated as described above (i.e., one ascospore from each ascus). The resulting $F_{1}$ population was composed of 78 cultures (derived from 78 asci).

These cultures were maintained on sterilized barley seed media (4) under dry condition at $4^{\circ} \mathrm{C}$ for long-term storage. Just before use for experiments, a barley grain with mycelia was transferred to potato dextrose agar (PDA) (24 g of potato dextrose broth powder [Difco, Sparks, MD] and $15 \mathrm{~g}$ of agar powder [Nakalai Tesque, Kyoto, Japan] in 1 liter of water) in a test tube, and incubated at $25^{\circ} \mathrm{C}$.

Plant materials. T. aestivum Norin 4 was used for the determination of genotypes of the $\mathrm{BC}_{1} \mathrm{~F}_{1}$ cultures. In addition, 28 hexaploid wheat cultivars or accessions $(2 n=6 \mathrm{X}=42$, genome AABBDD), 28 tetraploid wheat accessions $(2 n=4 \mathrm{X}=28$, genome AABB or AAGG), and four barley cultivars (Hordeum vulgare $\mathrm{L}$., $2 n=2 \mathrm{X}=14$, genome $\mathrm{HH}$ ) (Tables 1 and 2) were used to examine the effect of $P W T 1$. Seed were pregerminated on moistened filter paper for 1 day, then sown in a seedling case (5.5 by 15 by $10 \mathrm{~cm}$ ) filled with vermiculite (Asahi-Kogyo, Okayama, Japan) and grown at $21^{\circ} \mathrm{C}$ in a growth chamber with a 12 -h photoperiod for 7 days.

Infection assay. $M$. oryzae cultures were grown on oatmeal agar media in petri dishes in darkness at $25^{\circ} \mathrm{C}$ for 6 days. Aerial mycelia on the 6-day-old cultures were washed off by rubbing mycelial surfaces with cotton balls. The colonies were exposed to near-ultraviolet light $(360 \mathrm{~nm}, 40 \mathrm{~W})$ at $25^{\circ} \mathrm{C}$ for 4 days to induce sporulation (12). The conidia produced were suspended in water and adjusted to $1 \times 10^{5}$ spores $/ \mathrm{ml}$ (low concentration) or $2 \times$ $10^{5}$ spores $/ \mathrm{ml}$ (high concentration). Spore suspension $(10 \mathrm{ml})$ with $0.01 \%$ Tween 20 (Nakalai Tesque) were sprayed on the adaxial surface of the 7-day-old primary leaves in a plastic case with an air compressor. The cases were sealed to maintain high humidity and placed in darkness for $24 \mathrm{~h}$ at 23 to $24^{\circ} \mathrm{C}$. The inoculated plants were then transferred to a growth chamber at 23 to $24^{\circ} \mathrm{C}$ with a 12 -h photoperiod. At 4 to 6 days after inoculation, symptoms were evaluated based on the color and the size of lesions (29). The size was rated using six progressive grades from 0 to 5: 0 , no visible evidence of infection; 1 , pinpoint spots; 2 , small lesions $(<1.5 \mathrm{~mm}) ; 3$, lesions with an intermediate size ( $<3 \mathrm{~mm}$ ); 4, large, typical lesions; and 5, complete blighting of leaf blades. These lesions were classified into two categories on the basis of their color, brown (B) and green (G). Infection types were represented by the combination of the size and color. For example, infection type 3B represents brown lesions of size 3 . When several types of lesions appeared on a single leaf, the infection type was determined according to the predominant type. Six plants per line were evaluated for each isolate per replication. The pathogenicity test was repeated at least three times.

Southern blot analysis. Total genomic DNA was isolated as described by Nakayashiki et al. (13). The DNA samples were digested with restriction enzymes (Takara, Kyoto, Japan), electrophoresed on an agarose gel in 0.5x Tris-borate-EDTA buffer, blotted onto a Hybond N+ filter (GE Healthcare, Buckinghamshire, U.K.) and fixed by UV irradiation.

Probes were an rDNA clone (pZS9D10-rDNA-S); chromosome-specific markers (15) provided by S. A. Leong, University of Wisconsin-Madison, and M. L. Farman, University of Kentucky; cosmid clones derived from a genomic library of $\mathrm{Br} 48$; rDNA-associated genes (MGG_11011 and MGG_11012), pex genes (28); and a synthetic oligonucleotide (TTAGGG) 10 for telomere repeats. The rDNA clone, pZS9D10-rDNA-S, was constructed by liberating a 8.4-kb Sall fragment with a single repeat of rDNA from a BAC clone, ZS9D10, (among a genomic library of GFSI1-7-2) and then by inserting the fragment into the SalI site of pBluescriptII SK(+). This rDNA clone, the chromosomespecific markers, and the cosmid clones of $\mathrm{Br} 48$ were labeled using the ECL Direct Nucleic Acid Labeling and Detection System (GE Healthcare). The rDNA-associated genes were chosen from supercontig 1 of the M. oryzae (strain 70-15) genome sequence in the database ( $e$-Xtra). They were amplified from genomic DNA of GFSI1-7-2 with primers listed in Table 3 in a 50- $\mu$ reaction containing 1 unit of KOD-plus DNA polymerase (TOYOBO, Osaka, Japan), $1 \times$ polymerase chain reaction (PCR) buffer for KOD-plus provided by the manufacturer, $200 \mu \mathrm{M}$ each dNTP, $0.3 \mu \mathrm{M}$ each primer, $1 \mathrm{mM} \mathrm{MgSO}$, and $5 \mathrm{ng}$ of template DNA. This reaction was run by Mastercycler gradient (Eppendorf, Hamburg, Germany) programmed for $2 \mathrm{~min}$ at $94^{\circ} \mathrm{C}$ and 30 cycles of $15 \mathrm{~s}$ at $94^{\circ} \mathrm{C}, 30 \mathrm{~s}$ at $56^{\circ} \mathrm{C}$, and $1 \mathrm{~min}$ at $68^{\circ} \mathrm{C}$. Amplified fragments were directly labeled using the ECL Direct kit described above. Pex genes were genes encoding putative secreted proteins which were present in Ina168, an Oryza isolate of $M$. oryzae collected in Japan but absent in the assembled sequence of strain $70-15$ in the database. In a preliminary screening of $\approx 300$ pex genes using primers reported by Yoshida et al. (28), we found three pex genes (pex054, pex150, and pex317) that were closely linked to the rDNA locus. These genes were amplified from genomic DNA of Ina168 with primers listed in Table 3 in the same condition as for the rDNA-associated genes, and the amplicons were directly labeled using the ECL Direct kit. The telomere probe was labeled using the Alkphos direct labeling and detection system (GE Healthcare) because a high sensitivity was needed. Southern hybridization and detection of the genomic DNA was performed using these kits according to the manufacturer's instructions. 
PCR analysis. Segregation analysis of the rDNA locus was also conducted using PCR. Based on a single-nucleotide polymorphism in the rDNA repeat of GFSI1-7-2 and Br48 (6), two primer sets were designed (Table 3); one was specific for the rDNA repeat of GFSI1-7-2 and the other was specific for that of $\mathrm{Br} 48$. Using these specific primers, rDNA was amplified in a $50-\mu 1$ reaction containing 1 unit of HotStarTaq DNA Polymerase (Qiagen, Hilden, Germany), 1× PCR buffer provided by the manufacturer, $200 \mu \mathrm{M}$ each $\mathrm{dNTP}, 0.1 \mu \mathrm{M}$ each primer, and $5 \mathrm{ng}$ of template DNA. This reaction was run by Mastercycler gradient (Eppendorf) programmed for $15 \mathrm{~min}$ at $95^{\circ} \mathrm{C} ; 30$ cycles of $30 \mathrm{~s}$ at $94^{\circ} \mathrm{C}, 30 \mathrm{~s}$ at $56^{\circ} \mathrm{C}$, and $1 \mathrm{~min}$ at $72^{\circ} \mathrm{C}$; followed by $10 \mathrm{~min}$ at $72^{\circ} \mathrm{C}$.
Amplified fragment length polymorphism analysis. Amplified fragment length polymorphism (AFLP) analysis was conducted using AFLP Analysis System for Microorganisms (Invitrogen, Carlsbad, CA) according to the manufacturer's instructions, with modifications in the selective amplification primers. Briefly, total DNA (200 ng) was digested with EcoRI and MseI and the adaptors were ligated to the ends of the restriction fragments. In total, 20 cycles of PCR were performed for preamplification $(30 \mathrm{~s}$ at $94^{\circ} \mathrm{C}, 1 \mathrm{~min}$ at $56^{\circ} \mathrm{C}$, and $1 \mathrm{~min}$ at $72^{\circ} \mathrm{C}$ ). Selective amplification was performed using EcoRI and $\mathrm{Mse}$ I primers that additionally contained one to three selective nucleotides at the $3^{\prime}$ ends (e-Xtra). The first phase of the selective amplification was in one

TABLE 1 . Responses of wheat cultivars or accessions to $\mathrm{BC}_{1} \mathrm{~F}_{1}$ testers derived from the backcross, $3 \mathrm{M} 2 \times \mathrm{Br} 48^{\mathrm{a}}$

\begin{tabular}{|c|c|c|c|c|c|c|c|c|c|c|}
\hline \multirow[b]{3}{*}{ Code } & \multirow[b]{3}{*}{ Species } & \multirow[b]{3}{*}{ Cultivar or accession } & \multirow[b]{3}{*}{ Genomes } & & & & \multicolumn{4}{|c|}{ No. of $\mathrm{BC}_{1} \mathrm{~F}_{1}$ cultures } \\
\hline & & & & \multicolumn{3}{|c|}{ Infection type with } & \multicolumn{2}{|c|}{$P W T 1$ carriers } & \multicolumn{2}{|c|}{ pwtl carriers } \\
\hline & & & & GFSI1-7-2 & $3 \mathrm{M} 2$ & $\mathrm{Br} 48$ & Avirulent & Virulent & Avirulent & Virulent \\
\hline 1502 & Triticum aestivum & Strain P168 & $\mathrm{ABD}$ & 2B & $5 B$ & $5 \mathrm{G}$ & 20 & 0 & 0 & 20 \\
\hline 1503 & T. aestivum & Chinese Spring & $\mathrm{ABD}$ & $1 \mathrm{~B}$ & $2 \mathrm{~B}$ & $5 \mathrm{G}$ & 20 & 0 & 0 & 20 \\
\hline 1504 & T. aestivum & Norin 26 & $\mathrm{ABD}$ & 0 & $4 B$ & $5 \mathrm{G}$ & 20 & 0 & 0 & 20 \\
\hline 1505 & T. aestivum & Strain Salmon & $\mathrm{ABD}$ & 0 & $2 \mathrm{~B}$ & $5 \mathrm{G}$ & 20 & 0 & 0 & 20 \\
\hline 1507 & T. aestivum & Selkirk & $\mathrm{ABD}$ & 0 & $1 \mathrm{~B}$ & $5 \mathrm{G}$ & 20 & 0 & 0 & 20 \\
\hline 1509 & T. sphaerococcum & KU161 & $\mathrm{ABD}$ & 0 & $1 \mathrm{~B}$ & $4 \mathrm{G}$ & 20 & 0 & 0 & 20 \\
\hline 1510 & T. compactum & KU151 & $\mathrm{ABD}$ & 1B & $3 B$ & $5 \mathrm{G}$ & 20 & 0 & 0 & 20 \\
\hline 1512 & T. macha & KU154 & $\mathrm{ABD}$ & 0 & $5 B$ & $5 \mathrm{G}$ & 20 & 0 & 0 & 20 \\
\hline 1513 & T. aestivum & Norin 29 & $\mathrm{ABD}$ & $1 \mathrm{~B}$ & $5 B$ & $5 \mathrm{G}$ & 20 & 0 & 0 & 20 \\
\hline 1515 & T. aestivum & Shin-chunaga & $\mathrm{ABD}$ & 0 & $2 \mathrm{~B}$ & $5 \mathrm{G}$ & 20 & 0 & 0 & 20 \\
\hline 1601 & T. aestivum & Hope & $\mathrm{ABD}$ & 0 & $3 B$ & $5 \mathrm{G}$ & 20 & 0 & 0 & 20 \\
\hline 1602 & T. aestivum & Timstein & $\mathrm{ABD}$ & 1B & $5 B$ & $5 \mathrm{G}$ & 20 & 0 & 0 & 20 \\
\hline 1603 & T. aestivum & Cheyenne & $\mathrm{ABD}$ & 0 & $1 \mathrm{~B}$ & $3 G$ & 20 & 0 & 0 & 20 \\
\hline 1835 & T. aestivum & Red Egyptian & $\mathrm{ABD}$ & 0 & $2 \mathrm{~B}$ & $5 \mathrm{G}$ & 20 & 0 & 0 & 20 \\
\hline H-1 & T. aestivum & Chancellor & $\mathrm{ABD}$ & 0 & $1 \mathrm{~B}$ & $3 \mathrm{G}$ & 20 & 0 & 0 & 20 \\
\hline $\mathrm{H}-11$ & T. aestivum & Renown & $\mathrm{ABD}$ & 0 & $2 \mathrm{~B}$ & $5 \mathrm{G}$ & 20 & 0 & 0 & 20 \\
\hline $\mathrm{H}-13$ & T. aestivum & Spica & $\mathrm{ABD}$ & 0 & 0 & $5 \mathrm{G}$ & 20 & 0 & 0 & 20 \\
\hline $\mathrm{H}-14$ & T. aestivum & Mendos & $\mathrm{ABD}$ & 0 & $3 B$ & $5 \mathrm{G}$ & 20 & 0 & 0 & 20 \\
\hline $\mathrm{H}-15$ & T. aestivum & Timvera & $\mathrm{ABD}$ & 0 & 0 & $5 \mathrm{G}$ & 20 & 0 & 0 & 20 \\
\hline $\mathrm{H}-16$ & T. aestivum & Transec & $\mathrm{ABD}$ & 0 & $2 \mathrm{~B}$ & $4 \mathrm{G}$ & 20 & 0 & 0 & 20 \\
\hline $\mathrm{H}-17$ & T. aestivum & Transfed & $\mathrm{ABD}$ & 0 & $4 B$ & $5 \mathrm{G}$ & 20 & 0 & 0 & 20 \\
\hline $\mathrm{H}-20$ & T. aestivum & Normandie & $\mathrm{ABD}$ & 2B & $5 B$ & $5 \mathrm{G}$ & 20 & 0 & 0 & 20 \\
\hline $\mathrm{H}-21$ & T. aestivum & Little Club & $\mathrm{ABD}$ & 1B & $3 B$ & $5 \mathrm{G}$ & 20 & 0 & 0 & 20 \\
\hline $\mathrm{H}-22$ & T. aestivum & Hard Federation & $\mathrm{ABD}$ & 0 & $5 B$ & $5 \mathrm{G}$ & 20 & 0 & 0 & 20 \\
\hline $\mathrm{H}-23$ & T. aestivum & Ramona 50 & $\mathrm{ABD}$ & 0 & $4 B$ & $5 \mathrm{G}$ & 20 & 0 & 0 & 20 \\
\hline $\mathrm{H}-24$ & T. aestivum & Mayo 64 & $\mathrm{ABD}$ & 0 & $2 \mathrm{~B}$ & $5 \mathrm{G}$ & 20 & 0 & 0 & 20 \\
\hline Tat-17 & T. aestivum & KU163 & $\mathrm{ABD}$ & 0 & $4 \mathrm{~B}$ & $4 \mathrm{G}$ & 20 & 0 & 0 & 20 \\
\hline Tat-19 & T. vavilovi & KU192 & $\mathrm{ABD}$ & 0 & 0 & $3 G$ & 20 & 0 & 0 & 20 \\
\hline St-11 & T. dicoccoides & KU108-1 & $\mathrm{AB}$ & $2 \mathrm{~B}$ & $5 \mathrm{G}$ & $5 \mathrm{G}$ & 0 & 20 & 0 & 20 \\
\hline St-12 & T. dicoccoides & KU109 & $\mathrm{AB}$ & $2 \mathrm{~B}$ & $5 \mathrm{G}$ & $5 \mathrm{G}$ & 0 & 20 & 0 & 20 \\
\hline St-13 & T. dicoccoides & KU110 & $\mathrm{AB}$ & $1 \mathrm{~B}$ & $5 \mathrm{G}$ & $5 \mathrm{G}$ & 0 & 20 & 0 & 20 \\
\hline St-14 & T. dicoccoides & KU195 & $\mathrm{AB}$ & 0 & $5 \mathrm{G}$ & $5 \mathrm{G}$ & 0 & 20 & 0 & 20 \\
\hline St-16 & T. dicoccum & KU111 & $\mathrm{AB}$ & $2 \mathrm{~B}$ & $5 \mathrm{G}$ & $5 \mathrm{G}$ & 0 & 20 & 0 & 20 \\
\hline St-27 & T. dicoccum & KU124 & $\mathrm{AB}$ & 2B & $5 \mathrm{G}$ & $5 \mathrm{G}$ & 0 & 20 & 0 & 20 \\
\hline St-28 & T. dicoccum & KU189 & $\mathrm{AB}$ & $1 \mathrm{~B}$ & $5 \mathrm{G}$ & $5 \mathrm{G}$ & 0 & 20 & 0 & 20 \\
\hline Tat-14 & T. paleocolchicum & KU156 & $\mathrm{AB}$ & $4 B$ & $5 \mathrm{G}$ & $5 \mathrm{G}$ & 0 & 20 & 0 & 20 \\
\hline St-29 & T. paleocolchicum & KU190-1 & $\mathrm{AB}$ & 2B & $5 \mathrm{G}$ & $5 \mathrm{G}$ & 0 & 20 & 0 & 20 \\
\hline St-30 & T. paleocolchicum & KU191 & $\mathrm{AB}$ & $3 B$ & $5 \mathrm{G}$ & $5 \mathrm{G}$ & 0 & 20 & 0 & 20 \\
\hline Tat-6 & T. durum & KU125 & $\mathrm{AB}$ & $1 \mathrm{~B}$ & $5 \mathrm{G}$ & $5 \mathrm{G}$ & 0 & 20 & 0 & 20 \\
\hline St-31 & T. durum & KU126 & $\mathrm{AB}$ & 3B & $5 \mathrm{G}$ & $5 \mathrm{G}$ & 0 & 20 & 0 & 20 \\
\hline St-35 & T. durum & KU130 & $\mathrm{AB}$ & $1 \mathrm{~B}$ & $5 \mathrm{G}$ & $5 \mathrm{G}$ & 0 & 20 & 0 & 20 \\
\hline St-36 & T. durum & KU132 & $\mathrm{AB}$ & $3 B$ & $5 \mathrm{G}$ & $5 \mathrm{G}$ & 0 & 20 & 0 & 20 \\
\hline St-38 & T. durum & KU136 & $\mathrm{AB}$ & $1 \mathrm{~B}$ & $5 \mathrm{G}$ & $5 \mathrm{G}$ & 0 & 20 & 0 & 20 \\
\hline St-39 & T. durum & KU301 & $\mathrm{AB}$ & $1 \mathrm{~B}$ & $5 \mathrm{G}$ & $5 \mathrm{G}$ & 0 & 20 & 0 & 20 \\
\hline St-41 & T. durum & KU329 & $\mathrm{AB}$ & $1 \mathrm{~B}$ & $5 \mathrm{G}$ & $5 \mathrm{G}$ & 0 & 20 & 0 & 20 \\
\hline St-43 & T. durum & KU459 & $\mathrm{AB}$ & $1 \mathrm{~B}$ & $5 \mathrm{G}$ & $5 \mathrm{G}$ & 0 & 20 & 0 & 20 \\
\hline Tat-11 & T. turgidum & KU147 & $\mathrm{AB}$ & $1 \mathrm{~B}$ & $5 \mathrm{G}$ & $5 \mathrm{G}$ & 0 & 20 & 0 & 20 \\
\hline St-46 & T. turgidum & KU149 & $\mathrm{AB}$ & $2 \mathrm{~B}$ & $5 \mathrm{G}$ & $5 \mathrm{G}$ & 0 & 20 & 0 & 20 \\
\hline Tat-7 & T. orientale & KU137 & $\mathrm{AB}$ & $4 \mathrm{~B}$ & $5 \mathrm{G}$ & $5 \mathrm{G}$ & 0 & 20 & 0 & 20 \\
\hline Tat-9 & T. polonicum & KU141 & $\mathrm{AB}$ & $3 B$ & $5 \mathrm{G}$ & $5 \mathrm{G}$ & 0 & 20 & 0 & 20 \\
\hline St-48 & T. polonicum & KU142 & $\mathrm{AB}$ & $2 \mathrm{~B}$ & $5 \mathrm{G}$ & $5 \mathrm{G}$ & 0 & 20 & 0 & 20 \\
\hline St-49 & T. polonicum & KU143 & $\mathrm{AB}$ & $3 B$ & $5 \mathrm{G}$ & $5 \mathrm{G}$ & 0 & 20 & 0 & 20 \\
\hline St-50 & T. polonicum & KU144 & $\mathrm{AB}$ & $2 \mathrm{~B}$ & $5 \mathrm{G}$ & $5 \mathrm{G}$ & 0 & 20 & 0 & 20 \\
\hline Tat-18 & T. abyssinicum & KU185 & $\mathrm{AB}$ & 0 & $5 \mathrm{G}$ & $5 \mathrm{G}$ & 0 & 20 & 0 & 20 \\
\hline St-57 & T. abyssinicum & KU186 & $\mathrm{AB}$ & 2B & $5 \mathrm{G}$ & $5 \mathrm{G}$ & 0 & 20 & 0 & 20 \\
\hline Tat-3 & T. timopheevi & KU107-1 & $\mathrm{AG}$ & $2 \mathrm{~B}$ & $5 \mathrm{G}$ & $5 \mathrm{G}$ & 0 & 20 & 0 & 20 \\
\hline
\end{tabular}

a Conidial suspension was adjusted to the low concentration $\left(1 \times 10^{5}\right.$ spores $\left./ \mathrm{ml}\right)$. 
cycle $\left(30 \mathrm{~s}\right.$ at $94^{\circ} \mathrm{C}, 30 \mathrm{~s}$ at $65^{\circ} \mathrm{C}$, and $1 \mathrm{~min}$ at $\left.72^{\circ} \mathrm{C}\right)$. The second touchdown phase was in 12 cycles, with the annealing temperature decreasing stepwise from 64.3 to $56.6^{\circ} \mathrm{C}$. The last phase was in 23 cycles $\left(30 \mathrm{~s}\right.$ at $94^{\circ} \mathrm{C}, 30 \mathrm{~s}$ at $56^{\circ} \mathrm{C}$, and $1 \mathrm{~min}$ at $72^{\circ} \mathrm{C}$ ). Amplified products were fractionated by electrophoresis through $6 \%$ denaturing polyacrylamide gels and stained using SILVER SEQUENCE DNA Staining Reagents (Promega Corp., Madison, WI).

Linkage analysis. Segregation data were analyzed using MAPMAKER Macintosh V2.0. Parameters for map construction were a minimum $\log$ of the likelihood ratio of 3.0 and a maximum recombination fraction of 0.4 . The Kosambi mapping function was employed to compute recombination distances in centimorgans $(\mathrm{cM})$.

\section{RESULTS}

Production of $\mathrm{BC}_{1} \mathrm{~F}_{1}$ cultures and determination of their genotypes. $P w t l$ was identified by inoculating a hexaploid wheat cultivar, Norin 4 , with the $F_{1}$ cultures derived from the cross GFSI1-7-2 × Br48 (12). Briefly, GFSI1-7-2 was avirulent on Norin 4 (infection type 0) while $\mathrm{Br} 48$ was virulent (infection type $5 \mathrm{G})$. In the $\mathrm{F}_{1}$ population, cultures producing brown lesions and those producing green lesions segregated in a $1: 1$ ratio $\left(35: 34, \chi^{2}\right.$ $[1: 1]=0.01,0.9<P)$. This locus associated with the lesion color was designated Pwtl as described above. However, the segregation of avirulence and virulence in the $F_{1}$ population was complex due to the involvement of another locus, Pwt 2 , which was associated with the lesion number (12). To exclude the effect of Pwt2 from the segregation, $3 \mathrm{M} 2$, an $\mathrm{F}_{1}$ culture with the PWT1;pwt2 genotype, was backcrossed with the Triticum isolate $\mathrm{Br} 48$ (pwt1;pwt2). In total, $63 \mathrm{BC}_{1} \mathrm{~F}_{1}$ cultures were obtained from this cross. Each of these cultures was derived from a distinct ascus and, therefore, from an independent meiotic event.

To determine an appropriate inoculum concentration and the border between avirulent and virulent reactions, Norin 4 and
Chinese Spring were inoculated with conidial suspensions of 3M2 prepared at various concentrations. Murakami et al. (12) performed their infection assays using suspensions adjusted to $2 \times$ $10^{5}$ spores $/ \mathrm{ml}$. When inoculated at this concentration (the high concentration), Norin 4 showed the 5B type (the $\mathrm{B}+$ type in Murakami et al. [12]) (Fig. 1). When the concentration was decreased, the size of the predominant lesions decreased concomitantly. At $1 \times 10^{5}$ spores $/ \mathrm{ml}$ (the low concentration), the infection type on Norin 4 was 4B (Fig. 1). Interestingly, the 4B type was observed on Chinese Spring inoculated at the high concentration and, in turn, the infection type on this cultivar changed to $2 \mathrm{~B}$ with the decrease of the inoculum concentration (Fig. 1). These results suggest that the lesion size score fluctuates with the inoculum concentration.

Leaves with the 5B type were completely shriveled and heavily damaged (Fig. 1). However, when these leaves were incubated in a moist condition, no conidia were produced, supporting the idea that type $5 \mathrm{~B}$ is a resistant reaction. Consequently, infection types $0,1 \mathrm{~B}, 2 \mathrm{~B}, 3 \mathrm{~B}, 4 \mathrm{~B}$, and $5 \mathrm{~B}$ were considered avirulent (or resistant) while infection types with "G" were considered virulent (or susceptible). When various wheat cultivars or accessions were inoculated with $3 \mathrm{M} 2$ and $\mathrm{Br} 48$, infection types $3 \mathrm{G}, 4 \mathrm{G}$, and $5 \mathrm{G}$ were observed but $1 \mathrm{G}$ or $2 \mathrm{G}$ never occurred (Table 1 ). Consequently, possible infection types were considered to be 0 to $5 \mathrm{~B}$ (resistant) and $3 \mathrm{G}$ to $5 \mathrm{G}$ (susceptible). The subsequent infection assays were performed using the low concentration unless otherwise described.

When Norin 4 was inoculated with the $63 \mathrm{BC}_{1} \mathrm{~F}_{1}$ cultures, avirulent (infection type 0-5B) and virulent (infection type $3 \mathrm{G}$ $5 \mathrm{G})$ cultures segregated clearly in a $1: 1$ ratio $\left(37: 26, \chi^{2}[1: 1]=\right.$ $1.92,0.1<P<0.5$ ) (Fig. 2). Based on these reactions on Norin 4, the genotype of each culture was determined; the avirulent cultures were considered to be $P W T 1$ carriers $(P W T 1 ; p w t 2)$ while the virulent cultures were considered to be $p w t 1$ carriers ( $p w t 1 ; p w t 2)$.

Reactions of wheat and barley lines to PWT1. The 56 wheat lines (28 hexaploid cultivars or accessions and 28 tetraploid

TABLE 2. Responses of barley cultivars (Hordeum vulgare) to $\mathrm{BC}_{1} \mathrm{~F}_{1}$ cultures derived from the backcross, $3 \mathrm{M} 2 \times \mathrm{Br} 48^{\mathrm{a}}$

\begin{tabular}{|c|c|c|c|c|c|c|c|}
\hline \multirow[b]{3}{*}{ Cultivar } & & & & \multicolumn{4}{|c|}{ No. of $\mathrm{BC}_{1} \mathrm{~F}_{1}$ cultures } \\
\hline & \multicolumn{3}{|c|}{ Infection type with } & \multicolumn{2}{|c|}{$P W T 1$ carriers } & \multicolumn{2}{|c|}{ pwt1 carriers } \\
\hline & GFSI1-7-2 & $3 \mathrm{M} 2$ & $\mathrm{Br} 48$ & Avirulent & Virulent & Avirulent & Virulent \\
\hline H.E.S.4 & 0 & $2 \mathrm{~B}$ & $5 \mathrm{G}$ & 37 & 0 & 0 & 26 \\
\hline Nakaizumi-zairai & 0 & $2 \mathrm{~B}$ & $5 \mathrm{G}$ & 37 & 0 & 0 & 26 \\
\hline Kobinkatagi & $1-2 B$ & $1 \mathrm{~B}$ & $4-5 G$ & 37 & 0 & 0 & 26 \\
\hline Nepal & $1-2 B$ & $2 \mathrm{~B}$ & $4-5 G$ & 37 & 0 & 0 & 26 \\
\hline
\end{tabular}

a Conidial suspension was adjusted to the low concentration $\left(1 \times 10^{5} \mathrm{spores} / \mathrm{ml}\right)$.

TABLE 3. Primers used for mapping around the rDNA locus

\begin{tabular}{|c|c|c|c|c|}
\hline \multirow[b]{2}{*}{ Target gene } & \multirow[b]{2}{*}{ Template } & \multirow[b]{2}{*}{ Size of amplicon (bp) } & \multicolumn{2}{|r|}{ Primers } \\
\hline & & & Name & Sequence $\left(5^{\prime}-3^{\prime}\right)$ \\
\hline \multirow[t]{2}{*}{ MGG_11011 } & GFSI1-7-2 & 585 & 7015Sc1_3 & TCGACGAAGAAGGCCTG \\
\hline & & & $7015 \mathrm{Sc} 1 \_4$ & CATTCATCCCAGCCTTCAT \\
\hline \multirow[t]{2}{*}{ MGG_11012 } & GFSI1-7-2 & 489 & 7015Sc1_5 & TGCTCATAAGTCAAAAGCGTC \\
\hline & & & 7015Sc1_6 & GTCCACGGCATTGAAATAC \\
\hline \multirow[t]{2}{*}{ pex054 } & Ina 168 & 506 & Ina168-pex54-Fa & TTAATTCAGCGAAAAAGT \\
\hline & & & Ina168-pex54-R ${ }^{a}$ & ATGGTACCGCAAATAGTT \\
\hline \multirow[t]{2}{*}{ pex 150} & Ina 168 & 195 & Ina168-pex150-Fa & TGGCGACAAAGAGGTG \\
\hline & & & Ina168-pex150-R ${ }^{\mathrm{a}}$ & GATGCACGGGGGAGAC \\
\hline \multirow[t]{2}{*}{ pex317 } & Ina168 & 175 & Ina168-pex317-Fa & CCTGGCCGTGACATCT \\
\hline & & & Ina168-pex317-R ${ }^{a}$ & GCGCGCAGGAAAGAC \\
\hline \multirow[t]{2}{*}{ rDNA in GFSI1-7-2 } & - & 516 & ITS_rd5 & CCGAGGTCAACCTTTAAAA \\
\hline & & & $\operatorname{ITS}^{\mathrm{b}}$ & GGAAGTAAAAGTCGTAACAAGG \\
\hline \multirow[t]{2}{*}{ rDNA in $\mathrm{Br} 48$} & - & 516 & ITS_rd6 & CCGAGGTCAACCTTTAAAG \\
\hline & & & ITS $5^{b}$ & GGAAGTAAAAGTCGTAACAAGG \\
\hline
\end{tabular}

a Yoshida et al. (28).

b White et al. (26). 


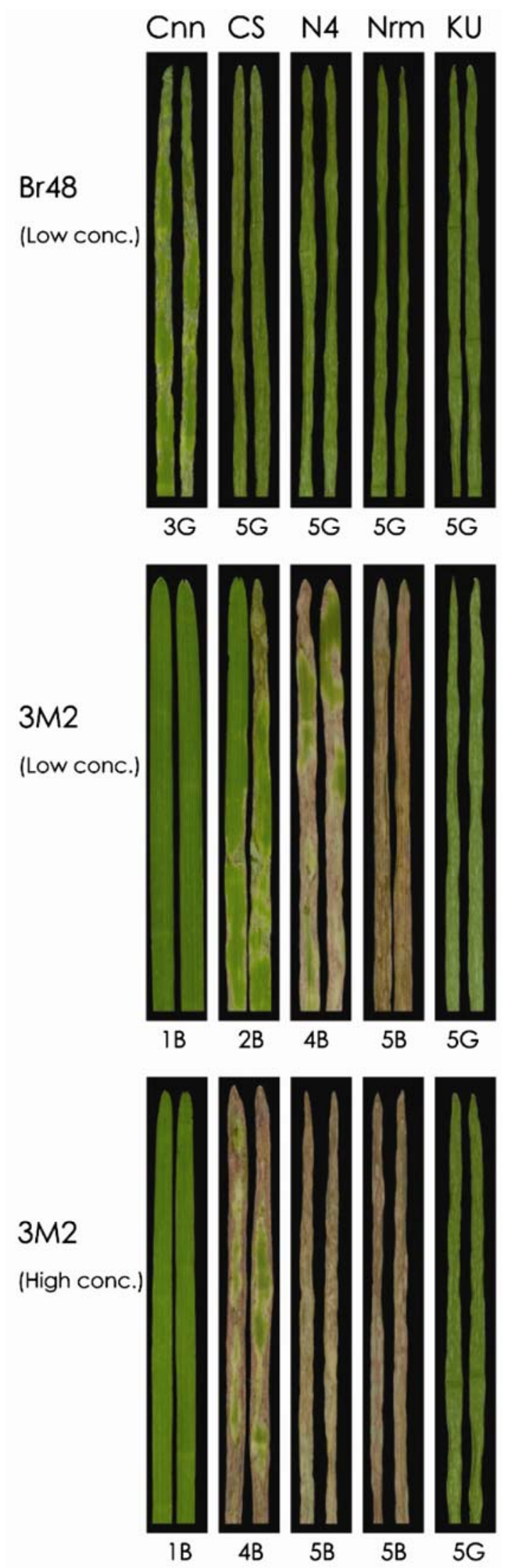

Fig. 1. Symptoms on seedlings of hexaploid cvs. Cheyenne (Cnn), Chinese Spring (CS), Norin 4 (N4), and Normandie (Nrm) and tetraploid accession KU108-1 (KU) inoculated with Magnaporthe oryzae Br48 and 3M2, 5 days after inoculation. Conidial suspension was adjusted to the low $\left(1 \times 10^{5}\right.$ spores $/ \mathrm{ml})$ or high $\left(2 \times 10^{5}\right.$ spores $\left./ \mathrm{ml}\right)$ concentration. accessions) were susceptible to the Triticum isolate $\mathrm{Br} 48$ and resistant to the Setaria isolate GFSI1-7-2 (Table 1). When they were inoculated with $3 \mathrm{M} 2$, the 28 hexaploid lines were all resistant whereas the 28 tetraploid lines were all susceptible (Table 1). Interestingly, there was a variation in the degree of resistance among the hexaploid lines (Fig. 1). When inoculated with $3 \mathrm{M} 2$ at the high concentration, the infection types of 'Cheyenne', Chinese Spring, Norin 4, and 'Normandie' were 1B, $4 \mathrm{~B}, 5 \mathrm{~B}$, and $5 \mathrm{~B}$, respectively. When inoculated at the low concentration, the difference among the four cultivars became more distinct: 1B, 2B, 4B, and 5B, respectively.

To examine whether the avirulence of $3 \mathrm{M} 2$ on these hexaploid lines was conditioned by $P W T 1,20 \quad \mathrm{BC}_{1} \mathrm{~F}_{1}$ cultures were arbitrarily chosen from each of the $P W T 1$ and the pwtl carriers, and the hexaploid lines were inoculated with the 40 testers. The hexaploid lines were all resistant to all of the PWT1 carriers and susceptible to all of the pwtl carriers (Table 1), suggesting that they recognize $P W T 1$. On the other hand, the tetraploid lines were all susceptible to all of the $\mathrm{BC}_{1} \mathrm{~F}_{1}$ testers (Table 1), indicating that they do not recognize $P W T 1$.

When barley cultivars were inoculated with the 40 testers, they showed the same pattern of reactions as the hexaploid lines (data not shown), suggesting that the barley cultivars also recognize $P W T 1$. To confirm it, they were inoculated with all of the $63 \mathrm{BC}_{1} \mathrm{~F}_{1}$ cultures. Again, they were resistant to all of the PWTl carriers and susceptible to all of the pwtl carriers (Table 2).

Mapping the Pwt1 locus using the $F_{1}$ population from GFSI1-7-2 $\times$ Br48. The $\mathrm{F}_{1}$ population produced by Murakami et al. (12) was composed of 10 tetrads or, in other words, was derived from only 10 meiotic events. For fine mapping, we crossed GFSI1-7-2 and Br48 again and produced a new $\mathrm{F}_{1}$ population composed of 78 cultures. Each of these cultures was derived from a distinct ascus and, therefore, from an independent meiotic event.

Using this fresh $F_{1}$ population, a linkage map of the cosmid, plasmid, and AFLP markers was constructed. The chromosome number of each linkage group was determined based on the chromosome-specific markers (15). Pwtl was mapped to a small linkage group carrying the rDNA locus (Fig. 3), which was reported to be located on chromosome 2 (15). This result suggests that Pwtl is located on chromosome 2. Chromosome 2 in this map was composed of two linkage groups; the small one carrying rDNA and a large one carrying a telomere marker (Tel-B5.1s) at one end (Fig. 3). It was reasonable to speculate that the other

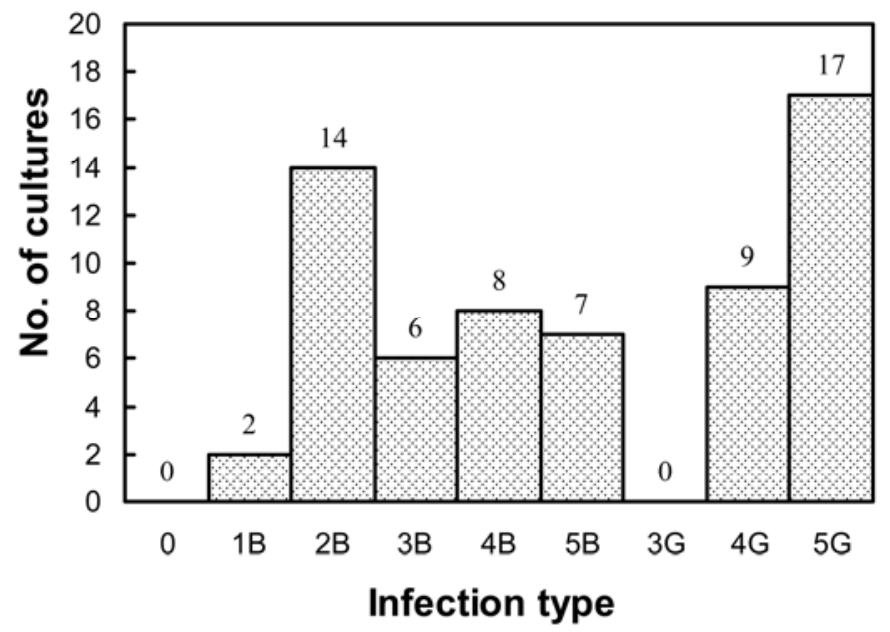

Fig. 2. Frequency distribution of infection types on hexaploid cv. Norin 4 in a $\mathrm{BC}_{1} \mathrm{~F}_{1}$ population derived from the cross $3 \mathrm{M} 2 \times \mathrm{Br} 48$. Conidial suspension was adjusted to the low concentration $\left(1 \times 10^{5}\right.$ spores $\left./ \mathrm{ml}\right)$. Avirulence: virulence $=37: 26, \chi^{2}(1: 1)=1.92(0.1<P<0.5)$. 
telomere should be on the small one but we could not find a telomere marker that was mapped to it.

The segregation of the rDNA locus was confirmed by PCR with both GFSI1-7-2-specific and Br48-specific primer pairs. The segregation at the Pwtl locus was confirmed by repeating the infection assay four times. When these data were combined, there occurred one recombinant ( $e$-Xtra), which produced $1.4 \mathrm{cM}$ of distance between the two loci (Fig. 3). To locate more markers around the rDNA locus, the 70-15 genome sequence in the database was surveyed. Two genes (MGG_11011 and MGG_11012) were found in supercontig 1 in which rDNA was located (e-Xtra). These genes cosegregated completely with rDNA (Fig. 3). The nucleotide sequence in supercontig 1 other than the two genes and rDNA was occupied by a retrotransposon and solo-LTRs of other retrotransposons, and contained no genes suitable for mapping (e-Xtra).

The three pex genes (pex054, pex150, and pex317) selected in the preliminary screening were also subjected to segregation analysis. Pex054 and Pex 150 cosegregated completely with rDNA and were located at the same locus as rDNA (Fig. 3). Between pex317 and rDNA, however, one recombinant was observed. Consequently, pex317 was located on the opposite side to Pwt1 with a distance of $1.4 \mathrm{cM}$ from rDNA. In other words, rDNA was flanked by Pex317 and Pwtl (Fig. 3).

When $\mathrm{A} 15 \mathrm{C} 10$, a marker located on the proximal side of rDNA, was analyzed together, this marker was located on the Pex317 side of the Pex317-rDNA-Pwtl linkage group (Fig. 3). This result suggests that $P w t l$ is located on the telomeric side of rDNA.

Mapping the Pwt1 locus using the $\mathrm{BC}_{1} \mathrm{~F}_{1}$ population developed from $3 \mathrm{M} 2 \times \mathbf{B r 4 8}$. Molecular mapping of Pwtl was further performed using the $\mathrm{BC}_{1} \mathrm{~F}_{1}$ population derived from $3 \mathrm{M} 2$ $\times \mathrm{Br} 48$. A Southern blot analysis with the rDNA probe is shown in Figure 4 as an example. The $\mathrm{SacI}$ digestion liberated a single fragment $(8.4 \mathrm{~kb})$ corresponding to a single unit of the rDNA repeats in $\mathrm{Br} 48$ but two fragments (4.8 and $3.6 \mathrm{~kb}$ ) in GFSI1-7-2 and $3 \mathrm{M} 2$. In the $\mathrm{BC}_{1} \mathrm{~F}_{1}$ population, these two types segregated in a 1:1 ratio. The segregation at the rDNA locus was perfectly concordant with the segregation at the Pwtl locus; all of the 37 cultures avirulent on Norin 4 had the 3M2 type signals whereas all of the 26 cultures virulent on Norin 4 had the Br48 type signal.

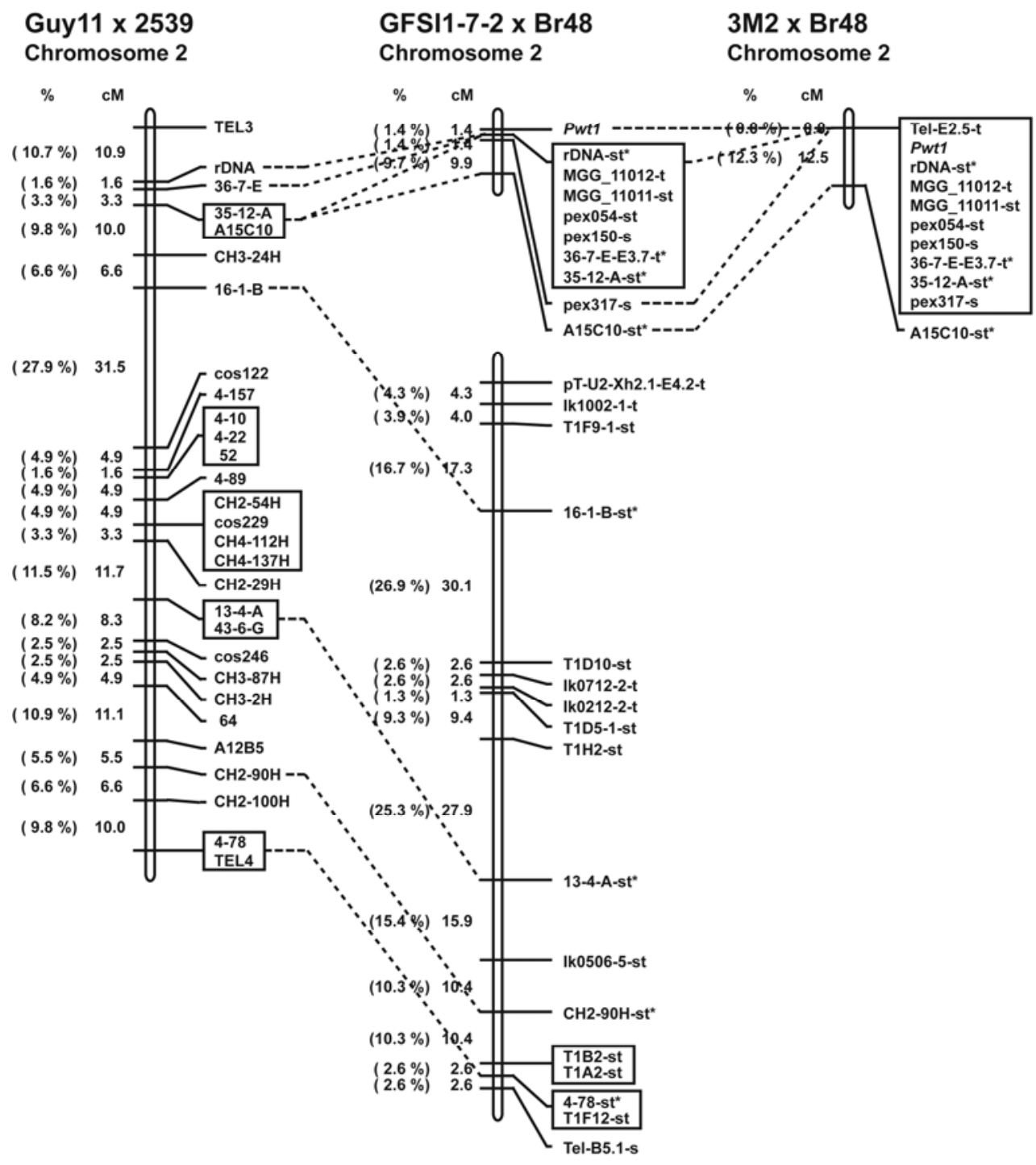

Fig. 3. Genetic mapping of the Pwt1 locus using an $\mathrm{F}_{1}$ population derived from GFSI1-7-2 $\times \mathrm{Br} 48$ and a $\mathrm{BC}_{1} \mathrm{~F}_{1}$ population derived from $3 \mathrm{M} 2 \times \mathrm{Br} 48$. Chromosome 2 in the $\mathrm{F}_{1}$ map is shown with a relevant linkage group of chromosome 2 in the $\mathrm{BC}_{1} \mathrm{~F}_{1}$ map. Asterisks indicate the chromosome 2-specific markers reported by Nitta et al. (15). Letters at the end of the markers (s and t) represent parents they are derived from. For example, MGG_11011-st represents cosegregating two fragments; that is, a fragment from GFSI1-7-2 (Setaria isolate) and a fragment from Br48 (Triticum isolate), which were visualized by hybridization with the MGG_11011 probe. Tel-E2.5-t represents a 2.5-kb EcoRI fragment from Br48 which was visualized by hybridization with the telomere probe. In this case, its counterpart (a cosegregating fragment derived from GFSI1-7-2) could not be detected. On the left is a standard map constructed from the segregation data in the Guy11 $\times 2539 \mathrm{~F}_{1}(15)$ using the same computer program, parameters, and mapping function as those used for the GFSI1-7-2 $\times$ Br48 and $3 \mathrm{M} 2 \times \mathrm{Br} 48$ maps. 
All of the other markers tightly linked to rDNA in the $F_{1}$ map (by 0 to $1.4 \mathrm{cM}$ ) cosegregated completely with rDNA (Fig. 3). Interestingly, a telomere signal (Tel-E2.5t) was found which consegregated with the rDNA locus in this $\mathrm{BC}_{1} \mathrm{~F}_{1}$ population (Fig. 3).

\section{DISCUSSION}

Results of infection assay with the blast fungus are affected by many factors (e.g., temperature, inoculum concentration, plant age, fertilizer, and so on). These factors are especially critical when we use young seedlings of winter crops such as wheat and barley. Takabayashi et al. (21) showed that the resistance of a wheat cultivar to an inappropriate pathotype of $M$. oryzae was temperature sensitive. Nga et al. (14) showed that the resistance of a wheat cultivar to an inappropriate species, M. grisea, was also temperature sensitive. Such temperature sensitivity was considered to be reasonable because wheat is a winter crop $(14,21)$. In the present study, we showed that the inoculum concentration was also important; infection types were strongly affected even by reducing the inoculum concentration to a half (Fig. 1). However, with the knowledge that the critical marker for resistance conferred by $P W T 1$ is the brown color, it is not difficult to differentiate resistant and susceptible lesions even when seedlings are inoculated with a high concentration of conidia. This colordependent determination of resistant and susceptible lesions may be applicable to PWT3, PWT4, and PWT5, other avirulence genes involved in the species specificity on wheat, because they are associated with hypersensitive reaction at the cytological level (unpublished data). The lesion size or damaged areas appear to be dependent on the number of germlings that successfully penetrated cell walls. In aged or adult plants, the number of such germlings should be much reduced by thick cell walls and the reaction induced by $P W T 1$ should be sufficient to protect the plants. The inoculum density-dependent fluctuation of lesion-size scores may be prominent only on young seedlings such as 7-dayold primary leaves used in our infection assay.

All of the hexaploid lines tested in the present study recognized $P W T 1$. This result suggests that $P W T 1$ is a fundamental gene that universally conditions the avirulence of Setaria isolates on hexaploid wheat. Furthermore, PWT1 was recognized by barley cultivars. This fact seems reasonable because PWT1 was identified as a gene controlling host species specificity. Interestingly, $P W T 1$ was not recognized by any of the tetraploid wheat lines. Further studies are needed to clarify why tetraploid wheat does not recognize $P W T 1$ although it shares A and B genomes with hexaploid wheat.

All of the hexaploid lines responded to PWT1 but the degree of the resistance differed from line to line. The level of resistance of the representative cultivars was Cheyenne $>$ Chinese Spring > Norin $4>$ Normandie (Fig. 1). We propose two alternative hypotheses for explaining these differences. Let us assume that $P W T 1$ is recognized by $R w t l$, a putative resistance gene corresponding to $P W T 1$ in a gene-for-gene manner. One hypothesis is that these cultivars have different alleles at the Rwt l locus that have suffered from various levels of degradation; Cheyenne has the strongest $R w t 1$ allele while Normandie has the weakest $R w t 1$ allele. The other is that these cultivars carry a strong, functional allele at the Rwtl locus but have various degrees of defects downstream of resistance mechanisms. To determine which is the case, Rwt 1 must be identified. Unfortunately, we could not find a hexaploid line that did not recognize $P W T 1$, a prerequisite for detecting $R w t l$. We are now trying to produce synthetic hexaploids that do not recognize PWT1 from tetraploid cultivars and Aegilops tauschii accessions.

In the $\mathrm{BC}_{1} \mathrm{~F}_{1}$ map, $P W T 1$ was completely linked to a telomere marker (Tel-E2.5t) (Fig. 3). This telomere signal was derived from $\mathrm{Br} 48$. Interestingly, this signal was absent in the $\mathrm{F}_{1}$ population from GFSI1-7-2 $\times$ Br48 produced in the present study. Furthermore, this signal was again found in the $F_{1}$ population from GFSI1-7-2 $\times$ Br48 produced by Murakami et al. (12) (data not shown). We assume that mycelial cells of Br48, which contributed to the sexual hybridization with GFSI1-7-2 in the present study, may have happened to lose this telomere fragment. This is not surprising because telomere fingerprint profiles are known to change frequently during vegetative growth (3). The loss of the telomere signal observed in the new $F_{1}$ population may be evidence that the reorganization or changes of telomeric regions occurs during vegetative growth on artificial solid media.

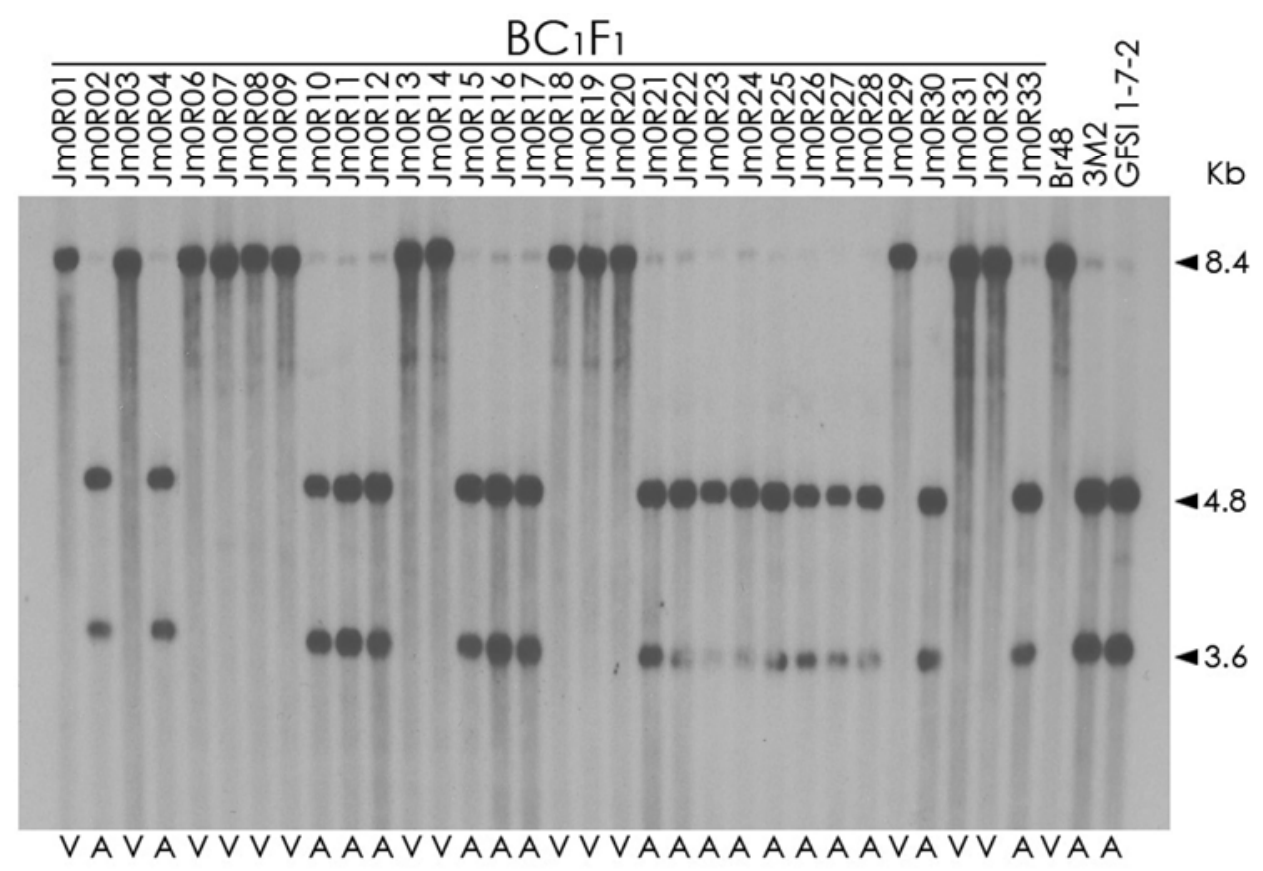

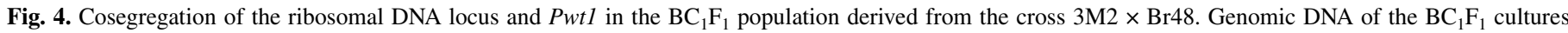

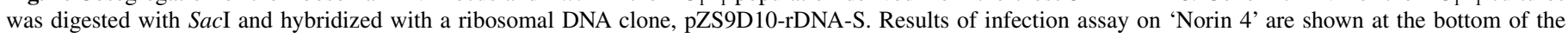
panel. A, avirulent; V, virulent. 
Avirulence genes involved in cultivar specificity tend to be located on subtelomeric regions $(11,17,25)$. PWL1, a cloned avirulence gene involved in species specificity on weeping lovegrass, was suggested to be linked to a telomere on the basis of cosegregation of a $P W L 1$-flanking sequence with a telomere signal (9). $P W L 2$, another cloned avirulence gene involved in species specificity on weeping lovegrass, was not closely linked to a telomere but was located on an unstable region which was rich in both high-copy and low-copy repeated DNAs (20). The present study showed that $P W T 1$, an avirulence gene involved in species specificity on wheat, is tightly linked to a telomere and probably located on a subtelomeric region. Based on these results, there seems to be no difference between avirulence genes involved in cultivar specificity and those involved in species specificity from the viewpoint of the instability of chromosomal regions in which they are located.

Are there differences between the two categories of avirulence genes from the viewpoint of their function or contribution to fitness? To answer this question, more avirulence genes must be cloned from both categories and compared. We started a project aiming at cloning $P W T 1$. Clues to the position of $P W T 1$ were not obtained from the genome sequence of $M$. oryzae strain 70-15 in the database. The supercontig 1 carrying rDNA in the database did not harbor any candidate genes ( $e$-Xtra). Moreover, there is a considerable possibility that PWT1 may not be present in the genome of 70-15. Yoshida et al. (28) tried to find avirulence genes corresponding to rice resistance genes in the 70-15 database sequence, but failed. They finally found three novel avirulence genes in $1.68-\mathrm{Mb}$ regions which were present in Ina168 but absent in the assembled sequence of 70-15. Chromosome walking is now underway from the rDNA locus toward PWT1.

\section{ACKNOWLEDGMENTS}

We thank H. Kato, a former professor at Kobe University, for providing the blast isolates and valuable suggestions; S. A. Leong, a professor at the University of Wisconsin, for providing the chromosomespecific markers of M. oryzae; M. Farman, a professor at the University of Kentucky, for providing information on some rDNA-linked markers and segregation data used for the Guy $11 \times 2539$ map; R. Terauchi and K. Yoshida, Iwate Biotechnology Research Center, for providing primers for the pex genes and detailed information on those genes; and K. Tsunewaki, M. Tanaka, and S. Sakamoto, emeritus professors at Kyoto University, and U. Hiura, an emeritus professor at Okayama University, for providing the wheat and barley lines.

\section{LITERATURE CITED}

1. Bryan, G. T., Wu, K. S., Farrall, L., Jia, Y., Hershey, H. P., McAdams, S. A., Faulk, K. N., Donaldson, G. K., Tarchini, R., and Valent, B. 2000. A single amino acid difference distinguishes resistant and susceptible alleles of the rice blast resistance gene Pi-ta. Plant Cell 12:2033-2045.

2. Couch, B. C., and Kohn, L. M. 2002. A multilocus gene genealogy concordant with host preference indicates segregation of a new species, Magnaporthe oryzae, from M. grisea. Mycologia 94:683-693.

3. Farman, M. L., and Kim, Y.-S. 2005. Telomere hypervariability in Magnaporthe oryzae. Mol. Plant Pathol. 6:287-298.

4. Hayashi, N., and Kato, H. 1988. Viability and aggressiveness of Pyricularia cultures preserved by silica gel-dried grain method. Proc. KantoTosan Plant Prot. Soc. 35:12-13. (In Japanese)

5. Heath, M. C. 1981. A generalized concept of host-parasite specificity. Phytopathology 71:1121-1123.

6. Hirata, K., Kusaba, M., Chuma, I., Osue, J., Nakayashiki, H., Mayama, S., and Tosa, Y. 2007. Speciation in Pyricularia inferred from multilocus phylogenetic analysis. Mycol. Res. 111:799-808.

7. Hirata, K., Tosa, Y., Nakayashiki, H., and Mayama, S. 2005. Significance of PWT4-Rwt4 interaction in the species specificity of Avena isolates of Magnaporthe oryzae on wheat. J. Gen. Plant Pathol. 71:340-344.

8. Jia, Y., McAdams, S. A., Bryan, G. T., Hershey, H. P., and Valent, B. 2000. Direct interaction of resistance gene and avirulence gene products confers rice blast resistance. EMBO J. 19:4004-4014.

9. Kang, S., Sweigard, J. A., and Valent, B. 1995. The $P W L$ host specificity gene family in the blast fungus Magnaporthe grisea. Mol. Plant-Microbe Interact. 8:939-948.

10. Kato, H., Yamamoto, M., Yamaguchi-Ozaki, T., Kadouchi, H., Iwamoto, Y., Nakayashiki, H., Tosa, Y., Mayama, S., and Mori, N. 2000. Pathogenicity, mating ability and DNA restriction fragment length polymorphisms of Pyricularia populations isolated from Gramineae, Bambusideae and Zingiberaceae plants. J. Gen. Plant Pathol. 66:30-47.

11. Luo, C. X., Yin, L. F., Koyanagi, S., Farman, M. L., Kusaba, M., and Yaegashi, H. 2005. Genetic mapping and chromosomal assignment of Magnaporthe oryzae avirulence genes AvrPik, AvrPiz, and AvrPiz-t controlling cultivar specificity on rice. Phytopathology 95:640-647.

12. Murakami, J., Tosa, Y., Kataoka, T., Tomita, R., Kawasaki, J., Chuma, I., Sesumi, Y., Kusaba, M., Nakayashiki, H., and Mayama, S. 2000. Analysis of host species specificity of Magnaporthe grisea toward wheat using a genetic cross between isolates from wheat and foxtail millet. Phytopathology 90:1060-1067.

13. Nakayashiki, H., Kiyotomi, K., Tosa, Y., and Mayama, S. 1999. Transposition of the retrotransposon MAGGY in heterologous species of filamentous fungi. Genetics 153:693-703.

14. Nga, N. T. T., Hau, V. T. B., and Tosa, Y. 2009. Identification of genes for resistance to a Digitaria isolate of Magnaporthe grisea in common wheat cultivars. Genome 52:801-809.

15. Nitta, N., Farman, M. L., and Leong, S. A. 1997. Genome organization of Magnaporthe grisea: Integration of genetic maps, clustering of transposable elements and identification of genome duplications and rearrangements. Theor. Appl. Genet. 95:20-32.

16. Oh, H. S., Tosa, Y., Takabayashi, N., Nakagawa, S., Tomita, R., Don, L. D., Kusaba, M., Nakayashiki, H., and Mayama, S. 2002. Characterization of an Avena isolate of Magnaporthe grisea and identification of a locus conditioning its specificity on oat. Can. J. Bot. 80:1088-1095.

17. Orbach, M. J., Farrall, L., Sweigard, J. A., Chumley, F. G., and Valent, B. 2000. A telomeric avirulence gene determines efficacy for the rice blast resistance gene Pi-ta. Plant Cell 12:2019-2032.

18. Rehmeyer, C., Li, W., Kusaba, M., Kim, Y.-S., Brown, D., Staben, C., Dean, R., and Farman, M. 2006. Organization of chromosome ends in the rice blast fungus, Magnaporthe oryzae. Nucleic Acids Res. 34:46854701.

19. Silue, D., Notteghem, J. L., and Tharreau, D. 1992. Evidence of a genefor-gene relationship in the Oryza sativa-Magnaporthe grisea pathosystem. Phytopathology 82:577-580.

20. Sweigard, J. A., Carroll, A. M., Kang, S., Farrall, L., Chumley, F. G., and Valent, B. 1995. Identification, cloning, and characterization of $P W L 2$, a gene for host species specificity in the rice blast fungus. Plant Cell 7:1221-1233.

21. Takabayashi, N., Tosa, Y., Oh, H. S., and Mayama, S. 2002. A gene-forgene relationship underlying the species-specific parasitism of Avenal Triticum isolates of Magnaporthe grisea on wheat cultivars. Phytopathology 92:1182-1188.

22. Tosa, Y., Hirata, K., Tamba, H., Nakagawa, S., Chuma, I., Isobe, C., Osue, J., Urashima, A. S., Don, L. D., Kusaba, M., Nakayashiki, H., Tanaka, A., Tani, T., Mori, N., and Mayama, S. 2004. Genetic constitution and pathogenicity of Lolium isolates of Magnaporthe oryzae in comparison with host species-specific pathotypes of the blast fungus. Phytopathology 94:454-462.

23. Tosa, Y., Tamba, H., Tanaka, K., and Mayama, S. 2006. Genetic analysis of host species specificity of Magnaporthe oryzae isolates from rice and wheat. Phytopathology 96:480-484.

24. Valent, B., and Chumley, F. G. 1991. Molecular genetic analysis of the rice blast fungus, Magnaporthe grisea. Annu. Rev. Phytopathol. 29:443467.

25. Valent, B., and Chumley, F. G. 1994. Avirulence genes and mechanisms of genetic instability in the rice blast fungus. Pages 111-134 in: Rice Blast Disease. R. S. Zeigler, S. A. Leong, and P. S. Teng, eds. CAB International, Wallingford, U.K.

26. White, T. J., Bruns, T., Lee, S., and Taylor, J. 1990. Amplification and direct sequencing of fungal ribosomal RNA genes for phylogenetics. Pages. 315-322 in: PCR Protocols: A Guide to Methods and Applications. M. A. Innis, D. H. Gelfand, J. J. Sninsky, and T. J. White, eds. Academic Press, San Diego, CA.

27. Yaegashi, H. 1978. Inheritance of pathogenicity in crosses of Pyricularia isolates from weeping lovegrass and finger millet. Ann. Phytopathol. Soc. Jpn. 44:626-632.

28. Yoshida, K., Saitoh, H., Fujisawa, S., Kanzaki, H., Matsumura, H., Yoshida, K., Tosa, Y., Chuma, I., Takano, Y., Win, J., Kamoun, S., and Terauchi, R. 2009. Association genetics reveals three novel avirulence genes from the rice blast fungal pathogen Magnaporthe oryzae. Plant Cell 21:1573-1591.

29. Zhan, S. W., Mayama, S., and Tosa, Y. 2008. Identification of two genes for resistance to Triticum isolates of Magnaporthe oryzae in wheat. Genome 51:216-221. 